\title{
Study on Structural Reliability Analysis of Aircraft Electronic Equipment
}

\author{
Daqian Zhang ${ }^{1,4, a^{*}}$, Qingchun Sun ${ }^{1,4, b}$, Jianguo Cui ${ }^{2, c}$, Dongsheng Liü ${ }^{3, d}$, \\ Xiao $\operatorname{Tian}^{3, e}$ \\ ${ }^{1}$ Key Laboratory of Liaoning Province for Composite Structural Analysis of Aerocraft and \\ Simulation, Shenyang Aerospace University ,Shenyang 110136, China \\ ${ }^{2}$ Institute of Automation, Shenyang Aerospace University, Shenyang 110136, China \\ ${ }^{3}$ Comprehensive Security, Shenyang Aircraft Design Institute, Shenyang 110035, China \\ ${ }^{4}$ Dept. Aerospace Engineering, Shenyang Aerospace University, Shenyang 110136, China \\ azhangdaqian65@163.com, bsunqingchunzhi@163.com, cgordon_cjg@163.com , \\ liudongsheng21@163.com, tianxiao32@163.com,
}

Keywords: Aircraft; Electronic equipment; Reliability analysis

Abstract. The aircraft electronic devices are mainly composed of plate type, the structures with so many electronic components are complex. Most electronic components are standard parts. Reliability analysis of aircraft electronic equipment is mainly focused on the circuit of electronic equipment and components and so on. However, the investigation about reliability of electronic equipment structure research is seldom. This article introduces the principle and method of structural reliability of aircraft electronic equipment. Taking the computer box of air data processing for a type of aircraft as an example, reliability analysis process is described based on Monte Carlo Method. the result of calculating the strength and stiffness reliability of the box are $99.9746 \%$ and $99.9833 \%$ respectively, while the experimental reliability are $99.9986 \%$ and $99.9918 \%$. The good consistency between simulation and experiment results indicates that the analysis method is reasonable and effective.

\section{Introduction}

With the development of economy, the aerospace industry has also made great progress. The performance of the aircraft electronic equipment tends to be growing better as the electronic technology developed [1]. Due to the particularity of aerospace electronic equipment's working environment, they require higher reliability than normal [2]. Low failure probability and long time running are required. Because of expenses and the experimental condition, it's impossible to evaluate the structural reliability through a large number of flight experiments, therefore, in order to ensure their working order and enhance their performance, the structure reliability analyses and designs of aircraft electronic equipment are necessary. However, for recent years, the engineering studies on structural reliability analysis of electronic equipment are relatively few and lag far behind the reliability research on electronic circuit and components [3-5]. This paper summarizes the existing reliability analysis methods of aircraft electronic equipment [6-10], and illustrates the basic methods of structural reliability simulation of aircraft electronic equipment by example.

\section{The classification of aircraft electronic equipment}

The typical aircraft electronic equipment includes box, base, printed circuit board and the basic electronic components. The basic electronic components include resistor, capacitor, inductance and the magnetic components, semiconductor discrete devices, relays, electric connector, semiconductor integrated circuit, hybrid integrated circuits and so on, which are usually fixed on the printed circuit board. And the printed circuit board generally includes PSU, MBI, CPU, AFU, DFU, PSU and SFU, and then it is fixed on the box by welding, bonding and plugging. The box is used for fixing printed circuit board, power supply, display device etc, the box and base are usually made together and the base is fixed on the aircraft. 


\section{The process of the reliability analysis}

Modeling. In the process of reliability analysis there must be random input variables and parametric modeling have to be done when the size of the structure, material properties are used as random variables.

Confirming the random variables. Generally, there are many random variables are involved in the process of reliability analysis, and generally they can be divided into three categories including the size of the structure, material properties and external effect(such as load, temperature change). Most of the random variables obey the normal distribution, and the statistic characteristics of random variables usually refer to the mean and variance.

Reliability calculating. Reliability analysis includes the reliability analysis of strength and stiffness.

Reliability of strength refers to that it is not allowed that stress exceeds the yield strength during work, otherwise it is considered failure. The equation of intensity state is shown in Eq. 1:

$$
Z=\sigma_{s}-\sigma_{\max } .
$$

$\sigma_{s}$ - yield strength of material, $\sigma_{\max }$-maximum equivalent stress during work.

Stiffness is an ability that elastic body resists deformation, and stiffness reliability refers to that the equipment in use are not allowed to appear that deformation exceeds the material allowable displacement, otherwise it is considered failure. The equation of stiffness state is shown in Eq. 2:

$$
G=\gamma_{S}-\gamma_{\max }
$$

$\gamma_{S}$-allowable displacement of material, $\gamma_{\max }$ —maximum displacement during work.

\section{Example analysis}

A case study of computer box of air data processing of an aircraft is given to describe reliability analysis process of aircraft electronic equipment.

Finite element analysis of the computer box of air data processing. The material of the is ZL101 [11], 10-nodes tetrahedron elements- SOLID187 are deploy parametric modeling by ANSYS software. It is shown in Fig. 1.

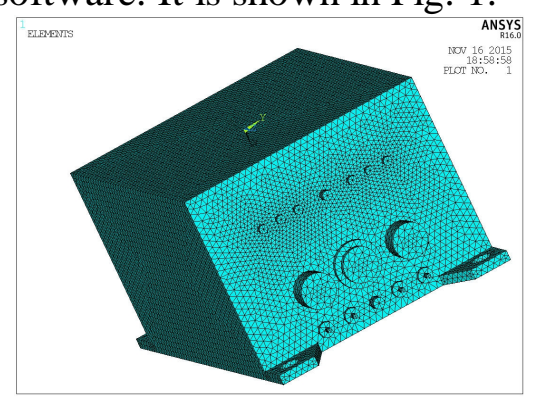

Fig. 1 The finite element model of computer box

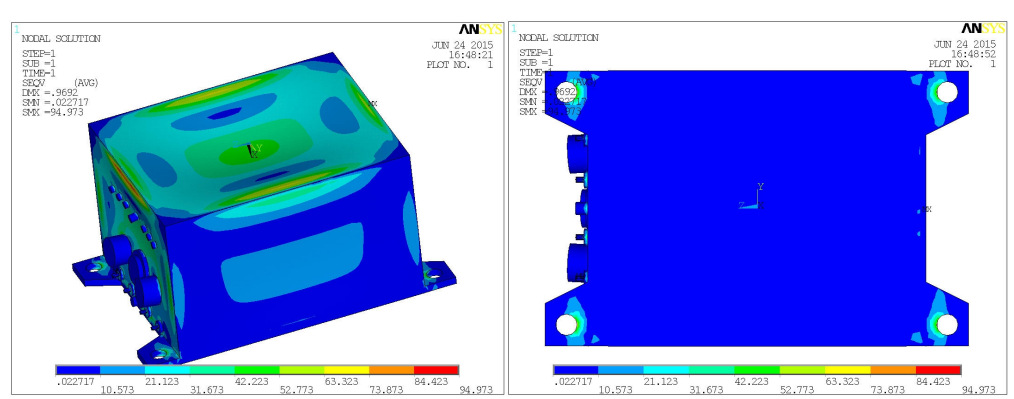

Fig. 2 The stress distribution of computer box

Stress analysis of the model is carried out after each random variable is averaged. It is shown in Fig. 2.

As is showed in the Fig. 2, the maximum stress is $94.973 \mathrm{MPa}$ at the edge of the upper cover of the box, and the stress in the area where the anchor bolts are fitted on is also high relatively, which make these area vulnerable to damage in repeated impact or a huge impact.

Reform the random variables and their distribution. Random variables of computer box of air data processing include the size of the structure, material properties and external load. According to the national standard about size tolerance, the size of box should obey truncated Gaussian distribution and the others obey the normal distribution. Unified unit: size $(\mathrm{mm})$, time $(\mathrm{s})$, force $(\mathrm{N})$, quality $(\mathrm{t})$, pressure(MPa). Random input variables are shown in Table 1. 
Table 1 Random input variables

\begin{tabular}{|c|c|c|c|c|c|}
\hline Random variables & Distribution function & mean & variance & $\begin{array}{l}\text { Upper } \\
\text { limit }\end{array}$ & $\begin{array}{l}\text { Lower } \\
\text { limit }\end{array}$ \\
\hline The length of box /d & $\begin{array}{c}\text { Truncated Gaussian } \\
\text { distribution }\end{array}$ & 316 & 1 & 314.8 & 317.2 \\
\hline The width of box /w & $\begin{array}{c}\text { Truncated Gaussian } \\
\text { distribution }\end{array}$ & 258 & 1 & 256.8 & 259.2 \\
\hline The height of box /h & $\begin{array}{c}\text { Truncated Gaussian } \\
\text { distribution }\end{array}$ & 191 & 1 & 189.8 & 192.2 \\
\hline $\begin{array}{l}\text { Box wall thickness } \\
\qquad / t_{1}\end{array}$ & $\begin{array}{c}\text { Truncated Gaussian } \\
\text { distribution }\end{array}$ & 4 & 0.1 & 3.7 & 4.3 \\
\hline $\begin{array}{l}\text { Box wall thickness } \\
\qquad / t_{2}\end{array}$ & $\begin{array}{c}\text { Truncated Gaussian } \\
\text { distribution }\end{array}$ & 7 & 0.1 & 6.5 & 7.5 \\
\hline $\begin{array}{l}\text { Box base thickness } \\
\qquad / t_{3}\end{array}$ & $\begin{array}{c}\text { Truncated Gaussian } \\
\text { distribution }\end{array}$ & 12 & 0.1 & 11.5 & 12.5 \\
\hline Cover thickness $/ t_{4}$ & $\begin{array}{c}\text { Truncated Gaussian } \\
\text { distribution }\end{array}$ & 5 & 0.1 & 4.7 & 5.3 \\
\hline $\begin{array}{l}\text { The density of } \\
\text { material }\end{array}$ & $\begin{array}{c}\text { Gauss normal } \\
\text { distribution }\end{array}$ & $2.7 \mathrm{e}-9$ & $2.7 \mathrm{e}-10$ & & \\
\hline $\begin{array}{l}\text { Modulus of } \\
\text { Elasticity }\end{array}$ & $\begin{array}{l}\text { Gauss normal } \\
\text { distribution }\end{array}$ & 70000 & 7000 & & \\
\hline Yield strength & $\begin{array}{l}\text { Gauss normal } \\
\text { distribution }\end{array}$ & 200 & 10 & & \\
\hline $\begin{array}{c}\text { Allowable } \\
\text { displacement }\end{array}$ & $\begin{array}{c}\text { Gauss normal } \\
\text { distribution }\end{array}$ & 2 & 0.2 & & \\
\hline Pressure & $\begin{array}{l}\text { Gauss normal } \\
\text { distribution }\end{array}$ & 0.08 & 0.008 & & \\
\hline Overload & $\begin{array}{c}\text { Gauss normal } \\
\text { distribution }\end{array}$ & 58800 & 5880 & & \\
\hline
\end{tabular}

Random output variables are strength performance function and stiffness performance function.

Reliability calculating. Monte Carlo method is chosen to simulate 40000 times in this example. According to the aircraft pitch test data, the biggest impact overload is about 6 . The strength and stiffness reliability is got with the maximum load (impact) and 0.8 times of standard atmospheric pressure.

Analysis of calculation results. The results of reliability is shown in Table 2:

Table 2 The results of reliability

\begin{tabular}{lcc}
\hline & strength & stiffness \\
\hline failure probability / $p_{f s}$ & $0.0254 \%$ & $0.0167 \%$ \\
\hline
\end{tabular}

As is shown from results that the average probability of $Z<0$ is $0.0254 \%$ when the confidence coefficient is $95 \%$, which means that the strength reliability of the air data computer box is $99.9746 \%$. The failure probability of stiffness is $0.0167 \%$, in other words, the stiffness reliability of the air data computer box is $99.9833 \%$, while the experimental reliability is $99.9986 \%$ and $99.9918 \%$, which validates the good consistency between simulation and experiment results.

The impact that each random input variable have on strength and stiffness performance function is shown in Fig. 3. 

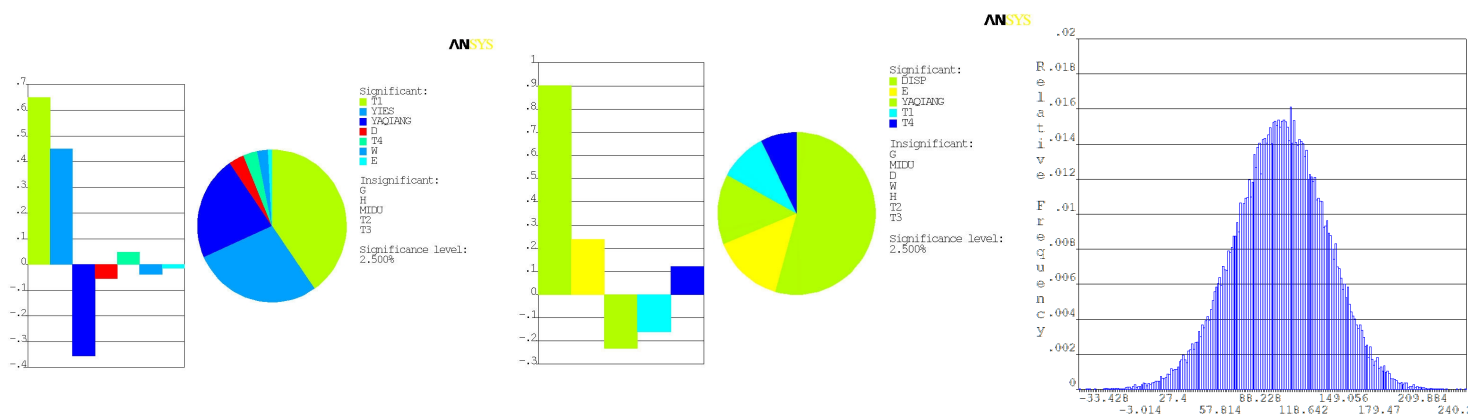

Fig. 3 Sensitivity of strength and stiffness performance function Fig. 4 Histogram of strength performance function

The Fig. 3 (left) shows that box wall thickness and yield strength YIES influence strength reliability of the box dramatically. The Fig. 3(right) shows that impact of allowable displacement have on the stiffness reliability of box is obvious, and the second one is the box wall thickness, so the basic size of box during production should obey to the standards strictly, and the high quality aluminum alloy materials should be used.

The Fig. 4 shows that it is consistent between the fitting curve of histogram of strength performance function and the distribution of the set random input variables, which indicates that the histogram curve of strength performance function is close to the normal probability density function as well as cycles sufficiently.

\section{Conclusion}

This paper introduces the principle and method of structural reliability analysis of aircraft electronic equipment, and using the reliability theory and stochastic finite element method could analyze and forecast structural reliability of aircraft electronic equipment accurately.

Technicians could early find problems by simulating structural reliability of the electronic equipment, and then optimize structure to improve the structural reliability of the products.

\section{References}

[1] Qiangjun Niu. Journal of xi 'an aviation technology college, 2011, 29(1):13-17. (In Chinese)

[2] Liangqiao Li, Xin Feng. Journal of Sichuan Ordnance, 2003, 24(2):6-10. (In Chinese)

[3] Jianxue Tian, Jungan Wei, bo zhao. Electronic design engineering, 2014, 22(24). (In Chinese)

[4] Ge Zhang, Qiaobing Ma. Electronic World, 2013, (22):9-11. (In Chinese)

[5] Jia Z Q, Cai J Y, Liang Y Y, et al. Systems Engineering-Theory \& Practice, 2010.

[6] Wei Li. Mechanical and electrical information, 2011, (18):157-158. (In Chinese)

[7] Yun hu. Telecommunication Engineering, 2012, 52(9):1532-1536. (In Chinese)

[8] Chaofeng Jiao. Electro-Mechanical Engineering, 2014, 30(2):16-18. (In Chinese)

[9] Ming Zhang. Structural reliability analysis-Methods and procedures. Beijing: Science press, 2009. (In Chinese)

[10] Yazhi Li, Meiying Zhao. The basis of finite element method and program design. Beijing: Science press, 2011. (In Chinese)

[11] Guang-cai Su, Zugao Pang, Haixiu Zhang, et al. Special Casting \& Nonferrous Alloys, 2010, 30(7):608-610. (In Chinese) 